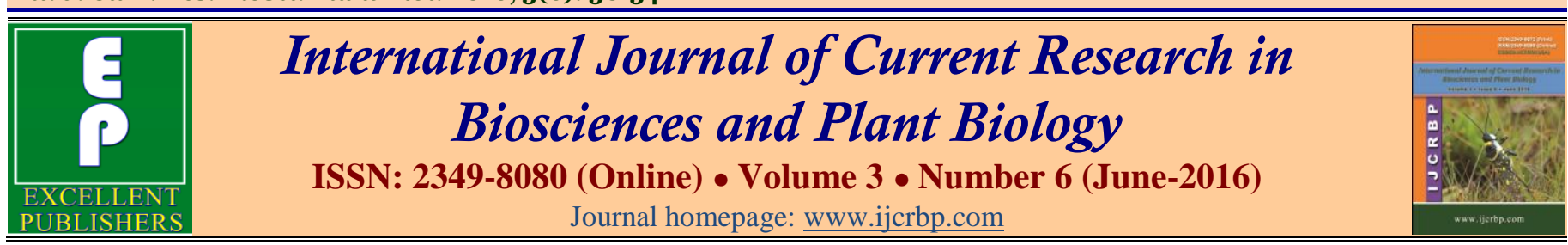

\title{
Blood Parameters and Liver Enzymes Levels as Index of Metabolic Changes in Response to Citrus aurantifolia
}

\author{
Edeke Affiong1, 2, Enomfon Akpan', Odiba Arome ${ }^{2 *}$, Anunobi Ogechukwu² and \\ Ukegbu Chimere ${ }^{2}$
}

${ }^{1}$ Department of Biochemistry, University of Uyo, Uyo, Nigeria

${ }^{2}$ Department of Biochemistry, University of Nigeria, Nsukka, Nigeria

*Corresponding author.

\begin{abstract}
The effects of extract of Citrus aurantifolia on some blood and liver parameters were examined. Graded doses $(20,40,60,80$ and $100 \mathrm{mg} / \mathrm{kg})$ of extracts were administered daily by stomach intubation to rats for 14 days and the effects on body weight, liver enzymes and some blood parameters were evaluated. The results showed significant decreases in alanine aminotransferase (ALT), aspartate aminotransferase (AST) and alkaline phosphatase (ALP) when compared to the control group. Urea level also decreased significantly when compared with the control. The ALT $(\mathrm{mMol} / \mathrm{l})$ values had a range of $0.4 \pm 0.1$ to $5.1 \pm 0.1$ for the test groups, and $0.9 \pm 0.9$ as the control value. The AST $(\mathrm{mMol} / \mathrm{l})$ values had a range of $0.1 \pm 0.28$ to $0.2 \pm 0.05$ for the test groups, and $0.6 \pm 0.09$ as the control value. The ALP $\mathrm{mMol} / \mathrm{l}$ values had a range of $0.7 \pm 0.13$ to $1.1 \pm 0.05$ for the test groups, and $1.5 \pm 0.02$ as the control value. Creantinine values had a range from 74.45 \pm 21.07 to $262.65 \pm 26.65$ for the test groups, and a value of $78.0 \pm 33.00$ for the control group. The results show that the extract had no significant effects $(p=0.05)$ on liver enzymes and the blood parameters considered. There was a significant decrease in platelet counts and slight increases in packed cell volume (PCV), haemoglobin, white and red blood cells. Platelet counts $\left(\times 10^{9} / 1\right)$ values ranged between $153.5 \pm 1.50$ and $275.0 \pm$ 25.00 for the test groups and $275.0 \pm 25.00$ for the control group. PCV (\%) values ranged from $38.0 \pm 8.0$ to $45.5 \pm 0.5$ for the test groups, and $41.0 \pm 0.00$ as the control group value. Haemoglobin $(\mathrm{mg} / \mathrm{dl})$ values ranged between $12.5 \pm 5.0$ and $15.2 \pm 0.17$ for the test groups and, $13.6 \pm 0.00$ as the control. WBC $\left(\times 10^{9} / l\right)$ values ranges between $5.4 \pm 1.2$ and $6.85 \pm$ 0.9 for the test groups and $5.3 \pm 0.5$ as the control. $\mathrm{RBC}\left(\times 10^{9} / \mathrm{l}\right)$ values also had a range of $5.15 \pm 0.1$ to $6.40 \pm 0.1$ for the test groups and $5.15 \pm 0.2$ for the control. These results suggests that the extract was not likely to produce toxic effects on the body system when given at normal therapeutic doses for a short - term, as evident in the liver enzymes levels and some blood parameters.
\end{abstract}

\section{Article Info}

Accepted: 19 May 2016

Available Online: 06 June 2016

\section{Ke y w o r d s}

Blood parameters

Citrus aurantifolia

Liver enzymes

Organ weight

Toxicity

\section{Introduction}

Herbal prescriptions and natural remedies are commonly employed in developing countries for the treatment of various diseases; this practice being an alternative way to compensate for some perceived deficiencies in orthodox pharmacotherapy (Zhu et al., 2002). Unfortunately, there is limited scientific evidence regarding safety and efficacy to back up the continued therapeutic application of these remedies. The rationale for their utilization has rested largely on long term clinical experience (Zhu et al., 2002). But now, with the upsurge in the use of 
herbal medicines, a thorough scientific investigation of these plants will go a long way in validating their folkloric usage. Plants parts such as leaves, barks stems, flowers, fruits and seeds are often used either singularly or in combination with other plants for treatment of disease. These plant parts or preparations are usually abortifacients, febrifuges etc. C. aurantifolia (Lime) is a citrus fruit and an excellent source of vitamin $\mathrm{C}$ and flavonoids which have unique antioxidant activities (Shrestha et al., 2012). C. aurantifolia, which belongs to the Rutaceae family, is believed to reduce oxidative stress by inhibiting cellular lipid peroxidation and increasing cellular antioxidant systems (Marzouk and Karoui, 2013). Apart from containing vitamin C and antioxidants, C. aurantifolia has high level of acid which helps in regulating the $\mathrm{pH}$ of water in the body and elements content (Timbrel, 2002). Notably, as increasing amounts of acids are added to the body, the $\mathrm{pH}$ of water in the body decreases and buffering capacity of water is consumed. The normal $\mathrm{pH}$ of $C$. aurantifolia is between 6.1 and 6.5 thus indicating acidity (Zhu et al., 2002). According to Zhu et al. (2002), as a result of acid contents of the fruit, if taken over long period of time, human body cells, tissues and organs may be damaged. These organs include the hearts, liver, kidney, pancreas, lungs, brain, muscles, and the skin nerve, which deteriorate in their functions. This can lead to distorted enzyme activities, impaired endocrine and biochemical activities. Also in the rural communities, the juice of $C$. aurantifolia has been greatly appreciated for its medicinal properties. Unlike conventional or orthodox medicine, the dose of this fruit extracts being used as drugs are not clearly stated. For this reasons, the rural dwellers in appreciation of the medicinal functions of this fruit use the extract haphazardly. These facts have necessitated this investigation to be carried out to determine the toxic effects of $C$. aurantifolia on blood parameters and some liver enzymes using albino rats.

\section{Materials and methods}

All reagents and chemicals that were used in this work were of analytical grade, and these reagents were products of Sigma-Aldrich (USA).

\section{Plant material}

Fresh fruits of Citrus aurantifolia (Lime) used in this research were obtained from an orchard located at the University of Uyo, Nigeria. The fruits were peeled then cut into fine shapes and dried at $121^{\circ} \mathrm{C}$. The dried fruits were grinned and extracted using ethanol. The extract was distilled in vacuo at $50^{\circ} \mathrm{C}$ giving a residue of $15 \mathrm{~g}$. The extract was stored and preserved in a refrigerator.

\section{Animals}

Twelve adults male Wistar strain of albino rats, weighing between 145-212 $\mathrm{g}$ were obtained from the Animal House of the Department of Pharmacology, University of Uyo and used for the study. The animals were maintained in a ventilated room at a room temperature of $28.0 \pm 2^{\circ} \mathrm{C}$ and natural lighting condition. The animals were fed with growers (pelleted) standard feed and had access to water. The animals were handled in accordance with the Guide for Care and Use of Laboratory Animals (CCAC, 2009) and the experimental protocol was approved by the Committee for Ethics in Animal Experimentation of the University of Uyo.

\section{Experimental design}

The animals were randomly distributed into six groups (n =6) with each group having two animals in each of the five test groups and two animals in the control group (group F). They were administered with different concentrations of $20,40,60,80$, and $100 \mathrm{mg} / \mathrm{kg}$ of extract respectively through stomach intubation for fourteen days. Group A, B, C, D and E received $20,40,60,80$ and $100 \mathrm{mg} / \mathrm{kg}$ respectively of the fruit extract of $C$. aurantifolia and Group F distilled water and was used as the control. At the end of the $C$. aurantifolia extracts administrations, the rats were sacrificed by suffocation using chloroform, and then were dissected to help collect blood samples. Blood was collected into EDTA bottles for the haematological parameters to be measured. Animal livers and kidneys were also removed and weighed.

\section{Serum assays}

Estimation of alanine aminotransferase (ALT) activity and aspartate aminotransferase (AST) activity were carried out accordingly to Reitman and Frankel (1957). Estimation of urea level (Fawcett and Scott, 1960) and estimation of creatinine level (Henry et al., 1974; CCAC, 1974) were also carried out. Whole blood collected into EDTA bottle was assayed for packed cell volume (PCV), white blood cell (WBC) counts and WBC differentials lymphocyte and neutrophil counts (Dacie and Lewis, 1984). Enzyme assays were determined by estimating serum alkaline phosphatase (ALP) activity (Babson, 1965; Imafidon and Okunrobo, 2012). All the methods are in accordance with the standards provided by the 
International Federation of Clinical Chemistry (IFCC) as updated and verified in 2007.

\section{Packed cell volume (PCV, Microhaematrocit method)}

Whole blood was gently and thoroughly mixed to give an even cell distribution before introducing the capillary tube in it. Blood enters the capillary tube by capillary action and the tube was filled with blood to about the quarter the length of the tube leaving $15 \mathrm{~nm}$ unfilled. Plastacine was used to seal off one free end of the tube and placed in a centrifuge. Centrifugation was for 5 minutes at $12,000 \mathrm{rpm}$. The capillary tube containing packed cell and plasma was positioned in the slot of the micro haematrocit reader so that the bottom line intersects the base of the sealed tube end. The knob was adjusted so that the middle line intersects top of the packed red cells. The percentage PCV was read on the graduated scale.

\section{Haemoglobin estimation}

Whole blood samples were thoroughly mixed by swirling and repeated inversion immediately before pipetting 20 $\mathrm{ml}$ of blood and adding $5 \mathrm{ml}$ of Drabskin's reagent, and the pipette which was externally wiped free of blood contamination was rinsed into Drabskin's reagents in a test tube. The reaction mixtures were left to stand a period of 15 minutes after which the absorbance was read at $540 \mathrm{~nm}$, against reagents blank using UV/V is spectrophotometer. The difference between the reagent blank and the test sample was recorded as the absorbance of the test. The standard cyanmethaemoglobin was also read in the same way as test and the absorbance recorded.

\section{Red blood cell and white blood cell counts}

A 1:200 dilution of blood was made in Hayem's fluid. This was done by sucking blood into RBC pipette up to 0.5 marks holding the pipette in horizontal position. The tip of the pipette was wiped with cotton wool to remove the super flows blood around it. The pipette was then dropped gently into Hayem's fluid and the fluid sucked into 101 marks. The blood and the diluting fluid were mixed with the help of the red bulb while swirling the pipette. The counting chamber was focused under low magnification and a cover slip placed on it. The clear solution in the stem on the RBC pipette was discarded and the chamber changed with the content of the RBC pipette. Counting was immediately carried out using four corners squares and the center square for RBC. In WBC count the fluid used is the Tunk's fluid but the dilution procedure was the same. The counting techniques differ instead of the 5 large square, cells are carried out in the four corners of the top and bottom large squares.

\section{Statistical analysis}

Data were expressed as Mean \pm SEM. Statistical differences between the groups were evaluated by one way ANOVA, followed by Dunnetts comparison test to compare between treated and control groups. Differences yielding $p<0.05$ were considered statistically significant.

\section{Results and discussion}

Changes in general behavior body weight and internal organ weight are critical for the objective evaluation of a compound on test animals, since such changes are often the first signs of toxicity. In acute toxicity study, after the administration of the extract from $C$. aurantifolia at a single dose of 20,40,60,80 and $100 \mathrm{mg} / \mathrm{kg}$ to the five group of rats, neither sign of toxicity nor death of rats was observed during the 14 days of experimental period. Neither body weight nor internal organ weight of treated rats was significantly changed to the control group (Table 1). From our findings, ALT concentrations were consistently higher than AST levels but more of AST than ALT (Padma and Ashok, 2010). Usually, about 80\% of AST is found in the mitochondria whereas ALT is a purely cytosolic enzyme and is considered a more sensitive marker of hepatocellular damage than AST and within limits can provide a quantitative assessment of the degree of damage sustained by the liver. In this study, the serum level of the aminotransferase (ALT and AST) did not show any significant increase $(p=0.05)$ when compared to the control group. Thus, indicating no cellular damage done to the liver since AST and ALT are good indicators of hepatic necrosis (Mayne, 1996). These results may indicate degenerative changes and hypofunction of liver and kidneys. In inflamamatory condition of the liver, the level ALT increase above that of AST. In this study, the level of ALT did not exceed AST levels in any of the treatment group and this shows that the liver is not damaged or affected. This result is in constant with the reported hepatoprotective effect of lime documented in various literatures (Abdel-Wahhab et al., 2002). Serum ALP is a measure of the integrity of the hepabiliary system and bone disease. The result of this experiment shows that there was no significant increment in the activity of the serum ALP in albino rats administered the extract compared to control. Lime has been reported to be rich in flavonoids which are known 
to exhibit antioxidant activity and are effective scavenger of superoxide anions (Del-Rio et al., 1997; Dixit et al., 2000). The extract may have exhibited hepatoprotectivity due to its antioxidant property attributed to flavonoid. Phytochemicals like synephine and octopamine are known to exhibit weight loss properties. These monoterpenes have been investigated to inhibit free radicals attaches on biomenbrane (Gathumbi et al., 2002). High amount of synephine has been reported to have significantly increased systolic and mean arterial pressure (Zimmerman, 2000). These enzymes are part of the body's protection against harmful substances. We could therefore infer from the investigations of this study that the effect of the extract on liver enzymes yielded no significant toxic effect on the hepatocytes and heart muscles. The results show dose dependent decrease in $\mathrm{PCV}$ and $\mathrm{Hb}$ (Table 2). There was no significant difference when compared with control while the slight increase might be due to over dehydration. This insignificant decrease may be due to the presence of certain phytochemical in the extract that inhibit the synthesis of haem. Red blood cells (RBC) count showed no significant $(p<0.05)$ difference from control. But its increase may be as a result of increase in erythropoietic activity of the animal. WBC is the component of blood responsible for phagocytic activity in the body, and it functions as defense machinery in eradicating foreign body. The level of WBC gives an indicator of foreign body. The recorded insignificant increase in the level of WBC indicates increase in the synthesis of WBC to combat foreign bodies. This also shows that the extract possesses phytochemicals that can modify autoimmune condition (Zhu et al., 2002). Platelet plays a major role in blood clotting. It shows an insignificant decrease in a dose - dependent manner when compared with control, this reduction may be due to presence of synephrine. The reduced level of urea probably indicates that it did not interfere with the renal capacity to excrete theses metabolites. It may also be a reflection of the renal integrity of treated rats (Kaneko, 1999).

Table 1. Mean levels of serum ALT, AST and ALP (nkat/l), urea (mmol/l) and creatinine $(\mu \mathrm{Mol})$

\begin{tabular}{|c|c|c|c|c|c|c|}
\hline Group & $\begin{array}{l}\text { Conc. } \\
(\mathrm{mg} / \mathrm{kg})\end{array}$ & $\begin{array}{l}\text { ALT (nkat/l) } \\
{[\text { mean } \pm \text { SD] }}\end{array}$ & $\begin{array}{l}\text { AST (nkat/l) } \\
{[\text { mean } \pm \text { SD] }}\end{array}$ & $\begin{array}{l}\text { ALP }(\text { nkat/l) } \\
\text { Mean } \pm \text { SD] }\end{array}$ & $\begin{array}{l}\text { Urea }(\mathbf{m m o l} / \mathbf{l}) \\
{[\text { mean } \pm \text { SD] }}\end{array}$ & $\begin{array}{l}\text { Creatinine }(\mu \mathrm{Mol}) \\
{[\text { mean } \pm \text { SD] }}\end{array}$ \\
\hline A & 20 & $0.4 \pm 0.10$ & $0.1 \pm 0.28$ & $0.9 \pm 0.05$ & $2.5 \pm 2.20$ & $262.65 \pm 26.65$ \\
\hline B & 40 & $5.1 \pm 0.20$ & $0.2 \pm 0.04$ & $1.1 \pm 0.05$ & $0.4 \pm 0.20$ & $75.85 \pm 0.00$ \\
\hline $\mathrm{C}$ & 60 & $0.7 \pm 0.20$ & $0.2 \pm 0.05$ & $0.7 \pm 0.13$ & $0.9 \pm 0.60$ & $137.70 \pm 30.90$ \\
\hline D & 80 & $0.4 \pm 0.20$ & $0.1 \pm 0.05$ & $0.9 \pm 0.01$ & $1.9 \pm 0.60$ & $95.50 \pm 19.60$ \\
\hline $\mathrm{E}$ & 100 & $0.4 \pm 0.20$ & $0.1 \pm 0.02$ & $0.9 \pm 0.24$ & $1.2 \pm 0.70$ & $74.45 \pm 21.07$ \\
\hline F (control) & - & $0.9 \pm 0.9$ & $0.6 \pm 0.09$ & $1.5 \pm 0.02$ & $54.0 \pm 5.00$ & $78.00 \pm 33.00$ \\
\hline
\end{tabular}

There was no significant difference $(p<0.05)$ in the above values of the parameters when compared with the control.

Table 2. Mean levels of blood cells parameters.

\begin{tabular}{llllll}
\hline Groups & Platelet & PCV $(\boldsymbol{\%})$ & HB $(\mathbf{m g} / \mathbf{d l})$ & WBC $(\mathbf{x 1 0} \boldsymbol{9} / \mathbf{l})$ & $\mathbf{R B C}(\mathbf{x 1 0} / \mathbf{l})$ \\
\hline A & $225.0 \pm 25.00$ & $38.5 \pm 0.50$ & $12.83 \pm 0.17$ & $5.70 \pm 0.40$ & $5.75 \pm 0.10$ \\
B & $228.5 \pm 71.50$ & $45.0 \pm 4.00$ & $15.00 \pm 33.00$ & $6.85 \pm 0.90$ & $6.40 \pm 0.10$ \\
C & $204.5 \pm 38.50$ & $45.5 \pm 0.50$ & $15.17 \pm 0.17$ & $5.7 \pm 0.50$ & $5.15 \pm 0.10$ \\
D & $153.5 \pm 1.50$ & $38.0 \pm 8.00$ & $12.50 \pm 0.50$ & $5.5 \pm 0.50$ & $5.75 \pm 0.10$ \\
E & $275.0 \pm 25.00$ & $40.0 \pm 4.20$ & $13.34 \pm 1.88$ & $5.4 \pm 0.20$ & $5.20 \pm 0.20$ \\
F (control) & $275.0 \pm 25.00$ & $41.0 \pm 0.00$ & $13.67 \pm 0.00$ & $5.3 \pm 0.50$ & $5.15 \pm 0.20$ \\
\hline
\end{tabular}

There was no significant difference $(p<0.05)$ in the above values of the parameters when compared with the control.

\section{Conclusion}

Every blood parameters determined in serum or plasma of experimental animals serves as indices to determine the biochemical state of the animal during the period of experiment. The changes may or may not reverse to normal depending on the nature of cellular damage that has taken place during the exposure period. A lower or higher value of one or more of these indices may or may not reveal any pathological defect. The level of utilization of $C$. aurantifolia in the third world countries is very high. The present investigation has attempted to ascertain the effect of ethanolic extract of $C$. aurantifolia on serum ALT, AST, ALP, urea, creatinine and some blood parameters in albino rats. The investigation showed no marked or significant decrease or increase in the result on all these biochemical parameter when compared with their control. 


\section{Conflict of interest statement}

Authors declare that they have no conflict of interest.

\section{Acknowledgement}

Authors wish to acknowledge the Department of Biochemistry, University of Uyo and University of Nigeria, for their help through the supply of equipment for this research.

\section{References}

Abdel-Wahhab, M.A., Nada, S.A., Khalil, F. A., 2002. Physiological and toxicological responses in rats fed aflatoxin-contaminated diet with or without sorbent materials. Anim. Feed Sci. Technol. 97(3-4), 209-219.

Babson, L.A., 1965. Estimation of alkaline phosphatase activity. Clin. Chem. 11, 789.

CCAC, 1974. The Care and Use of Farm Animals in Research, Teaching and Testing. CCAC., Ottawa, ON. pp.12-15.

Dacie, J.V., Lewis, S. N., 1984. Practical Haematology. $6^{\text {th }}$ Edn., Churchill Livingstone, Edinburg.

Dixit, V.P., Varma, M., Marthur, N.T., Marthur, R., Sharma, S., Hypocholesterolaemic and antiarterosclerotic effects of solasodine $\left(\mathrm{C}_{27} \mathrm{H}_{42} \mathrm{O}_{2} \mathrm{~N}\right)$ in cholesterol fed rabbits. Phytother. Res. 6, 279-273.

Fawcett, J. K., Scott, J.E., 1960. Na-K: Flame photometric method. J. Clin. Pathol. 3, 156-158.

Gathumbi, P. K., Mwangi, J. W., Mugera, G. M., Njiro, S.M., 2002. Toxicity of chloroform extract of Prumus africana stem bark in rats: Gross and histological lesions. Phytother. Res. 16, 244-247.

Henry, R.J., Cannon, D.C., Winkelman, W., 1974. Clinical Chemistry Principles and Techniques. $11^{\text {th }}$ Edn. Harper and Row, Hagerstown, MD.
Imafidon, K.E., Okunrobo, L.O., 2012. Study on biochemical indices of liver function tests of albino rats supplemented with three sources of vegetable oils. Niger. J. Basic Appl. Sci. 19(2), 105-110.

Del-Rio, J. A., Obdulio, B. G., Castillo, J., Marin, F. R., Ortuno, A., 1997. Uses and properties of Citrus flavonoids. J. Agric. Food Chem. 45(12), 4505-4514.

Kaneko, J. J., 1999. Clinical Biocchemistry. Domestic Publishers Inc., New York. 535p.

Marzouk, B., Karoui, I. J., 2013. Characterization of bioactive compounds in Tunisian bitter orange (Citrus aurantium L.) peel and juice and determination of their antioxidant activities. BioMed. Res. Int. 2013, Article ID 345415, $12 \mathrm{p}$.

Mayne, P. D., 1996. Clinical Chemistry in Diagnosis and Treatment. $6^{\text {th }}$ Edn. Edward Arnold, London.

Padma, S., Ashok, K. S., 2010. Cypermethrin induced biochemical alterations in the blood of albino rats. J. J. Biol. Sci. 3, 111-114.

Reitman, S., Frankel, S., 1957. Glutamic-pyruvate transaminase assay by colorimetric method. Am. J. Clin. Pathol. 28, 56-63.

Shrestha, R. L., Dhakal, D. M., Gautum, K. P., Shrestha, S., 2012. Variation of physiochemical components of acid lime (Citrus aurantifolia Swingle) fruits at different sides of the tree in Nepal. Am. J. Plant Sci. 3, 1688-1692.

Timbrel, J., 2002. Principles of Biochemical Toxicology. $3^{\text {rd }}$ Edn. Taylor and Francis, London. 187p.

Zhu, M., Lew, K. T., Leung, P., 2002. Protective effects of plant formula on ethanol-induces gastric lesions in rats. Phytother. Res. 16, 276-280.

Zimmerman, M. M., 2000. Phytochemicals: nutrient whose time has come. Nutr. Sci. News. http:/www.chiro.org/ Nutrition/FULL/phytochemicals.shtml.

\section{How to cite this article:}

Affiong, E., Akpan, E., Arome, E., Ogechukwu, A., Chimere, U., 2016. Blood parameters and liver enzymes levels as index of metabolic changes in response to Citrus aurantifolia. Int. J. Curr. Res. Biosci. Plant Biol. 3(6), 30-34. doi: http://dx.doi.org/10.20546/ijcrbp.2016.306.004 